\title{
Study On the Driven Mechanism of Watershed Hydrological Drought Based on Geomorphological Spatial Distribution Pattern: A Case Study of Guizhou, China
}

Zhonghua he ( $\nabla$ hezhonghua7621@126.com )

Guizhou Normal University

Hong Liang

Guizhou Normal University

Zhaohui Yang

Guiyang, Guizhou

\section{Research Article}

Keywords: hydrological drought, morphological index, spatial pattern, geomorphologic type, Guizhou province

Posted Date: July 13th, 2021

DOl: https://doi.org/10.21203/rs.3.rs-610334/v1

License: (c) (1) This work is licensed under a Creative Commons Attribution 4.0 International License.

Read Full License 


\title{
Study on the Driven Mechanism of Watershed Hydrological Drought Based on Geomorphological Spatial Distribution Pattern: A Case Study of Guizhou, China*
}

\author{
Zhonghua He ${ }^{1,2^{*}}$, Hong Liang ${ }^{1}$, Zhaohui Yang ${ }^{3}$ \\ 1. School of Geographic and Environment Science, Guizhou Normal University, Guiyang, Guizhou, 550001, China;
}

2.School of Geography and Environment -Sciences, Guizhou Normal University / State Engineering Technology Institute for Karst

Desertfication Control, Guiyang, Guizhou, 550001, China;

3. Department of Emergency Management of Guizhou Province, Guiyang, Guizhou, 550001, China;

\section{-Conflict of Interest:}

We declare that we have no financial and personal relationships with other people or organizations that can inappropriately influence our work, there is no professional or other personal interest of any nature or kind in any product, service and/or company that could be construed as influencing the position presented in, or the review of, the manuscript entitled, "Study on the Driven Mechanism of Watershed Hydrological Drought Based on Geomorphological Spatial Distribution Pattern: A Case Study of Guizhou, China”.

\section{-Funding Statement:}

This study was sponsored by the Natural Science Foundation of China (41471032; u1612441); Project for National Top Discipline Construction of Guizhou Province (85 2017 Qianjiao Keyan Fa); Project of National Key Innovation Base Construction （Qiankeheji Lab [2011]4001); Natural and scientific research fund of Guizhou Water Resources Department (KT201402); Natural and scientific fund of Guizhou Science and Technology Agency (QKH J [2010] No. 2026, QKH J [2013] No. 2208); 2015 Doctor Scientific Research Startup Project of Guizhou Normal University.

\section{-Author's Contribution:}

Zhonghua He was carrying out the works about the Research concept and design and Writing the article.Hong

* Corresponding author.

1,2Zhonghua He (1976-); male; born in Xingyi, Guizhou; doctor, professor, and master tutor; and mainly engaged in the study on karst hydrology, water resource, and remote sensing. 
Liang was carrying out the works about the works Collection and/or assembly of data and Data analysis and interpretation.Zhaohui Yang was carrying out the works about the works Critical revision of the article and Final approval of article.

\section{-Availability of data and material:}

The data and material used to support the findings of this study are available from the corresponding author upon request.

\section{-Code availability:}

'Not applicable' for this section.

\section{-Ethics approval:}

'Not applicable' for this section.

\section{-Consent to participate:}

All the authors consent to participate in the research of this paper.

\section{-Consent for publication:}

If this paper is accepted, I agree to publish it in this journal.

Abstract: In recent years, hydrological drought has become more and more frequent, which has caused serious ecological and environmental problems. This paper is taking Guizhou province of China as an example to analyze the geomorphologic distribution and temporal-spatial evolution of hydrological droughts, and to study driving mechanisms of both the rainfall in the dry periods and geomorphologic factor on the hydrological droughts, based on the hydrometeorological data during the years 2000-2010, and the TM and DEM data. The results show that (1) the rainfall and its variation in the low-flow seasons have less impacts on the hydrologic drought and its variation; (2) the hydrologic drought severity in Guizhou was increasing year by year during the years 2000-2010, and showing the inter-annual variation with obvious stage characteristics, and the regional hydrologic drought was presented the more serious in the South than in the North, and the less serious in the East than in the West; and (3) in terms of the overall distribution of landform types, the mountain, hill and basin have less impacts on hydrological droughts; in terms of the distribution of single geomorphic type, hydrological droughts are significantly influenced by the high-medium 
mountain, deep-high hill and high basin, where the hydrological droughts are relatively lighter. While there are more serious areas in the low basin, shallow-low hill and low mountain.

Keywords: hydrological drought; morphological index; spatial pattern; geomorphologic type; Guizhou province

\section{Introduction}

In recent years, droughts are a natural disaster threatening the safety of human life and property (EU, 2006, 2007;

Sheffield et al., 2011), like large-scale flood, earthquake, volcanic eruption and other disasters, and have become more and more frequent. The essence of droughts is the watershed water shortage, and the runoff recharges are mainly coming from the atmospheric precipitation, and the runoff recharge in the adjacent basins (for Karst basin). The volumes of watershed recharges are greatly affected by the rainfall volumes, while the effects of watershed landforms on the secondary distribution of atmospheric precipitation should not be underestimated. Especially it plays a crucial effect of the landform types and its morphological characteristics on the watershed recharge or infiltration volumes. The drought phenomena are very complex, such as dynamic with spatio-temporal distributions, and are influenced by human activities. Therefore, it is difficult to define and study the drought simply (Van Loon et al., 2012). Consequently, droughts are usually divided into four types, namely, meteorological drought, agricultural drought, hydrological drought and socio-economic drought (Van Huijgevoort et al.,2014;Van Lanen et al.,2013). Hydrological drought is the continuation and development of meteorological drought and agricultural drought, and is the final and most complete drought (Geng et al.,1992). It is the phenomenon that river runoff is below its threshold value due to the imbalance of precipitation and surface water or groundwater (Dracup et al.,1980; Feng 1993).

As for the present studies on hydrologic droughts, the theory of runs is firstly applied to quantitatively express the hydrological drought characteristics (Yevjevich, 1967), and to study the characteristics of extreme hydrological 
droughts obeying the normal and lognormal distributions (Sen,1977,1990 \& 1991; Guven,1983; Sharma,1998). Some

scholars utilize the different drought indices, such as Regional Dry Area Index (RDAI) based on daily runoff series, and Drought Potential Index (DPI), to analyze the characteristics of regional hydrological droughts (Fleig ,2011), and to study the relationship between the drought duration and intensity (Kim,2006; Panu,2009). Wen et al., (2011) employed the Standardized Runoff Index and Standardized Rainfall Index (SRIs) to study the influences of channel improvement and non-local diversion on the process and level of hydrologic droughts. The rank, process, and return period of hydrologic droughts are studied by utilizing Palmer Drought Index (PDI), Soil Moisture Model (SMM), Runoff Sequence $(R S)$, Standardized Rainfall Index $(S R I)$, and Vegetation Health Index (VHI) respectively (Nyabeze,2004; Mondal,2015). Some scholars make a time series analysis and random simulation for the hydrologic drought severities by an autoregression model (Abebe, 2008). The probability prediction of hydrological droughts is carried out using conditional probability distribution function based on the meta-Gaussian model (Hao et al.,2016). And Seibert et al., (2017) made the seasonal forecast of hydrologic droughts by a statistical analysis method in the Limpopo Basin. Rudd et al., (2017) was firstly to characterise the droughts by adopting a national-scale gridded hydrologic model across Great Britain over the last century. It is found in his research that the model can very well simulate low flows in many catchments across Great Britain. The threshold level method was also applied to identify historic droughts (1891-2015) based on the ime series of monthly mean river flow and soil moisture. At the same time, a few scholars explore the spatial-temporal distribution differences between the characteristics of the meteorological and hydrological droughts in terms of the basin scale (Hisdal, 2003). Among the domestic studies of hydrological droughts in China, the theory of runs is mainly applied to analyze the influential factors of runoff volume in dry season and the identification of hydrological droughts (Feng, 1997a), and to study the probability density and distribution functions of extreme hydrological drought duration (Feng, 1993,1994 \& 1995). The fractal theory is adopted to study the temporal fractal characteristics of hydrologic droughts, and to estimate the hydrologic drought severity by the time fractal dimension (Feng, 1997b). The Copula Joint Distribution Function is utilized to construct the joint distribution of hydrological 
drought characteristics (Zhou 2011; Xu, 2010; Ma, 2010). However, most of the researches are still to study the identification, feature analysis, prediction and forecast of hydrologic droughts by taking the different drought indices respectively. For example, Zhai et al., (2015) established a new hydrologic drought assessment index, i.e. Standard Water Resources Index (SWRI), and developed a basic framework of hydrologic drought identification, assessment and feature-analysis combined with the distributed hydrological model, Copula functions and statistical test methods. Zhao et al.,(2016) selected the optimum distribution from the logistic, normal, two-parameter log-normal, and Weibull probability distributions to establish the Standardized Streamflow Drought Index (SSDI), ranked the drought magnitudes of hydrologic drought events by the SSDI, and validated the applicability and rationality of the SSDI based on the actual drought situations in the Fenhe River Basin. By combining the percentages of runoff and precipitation anomalies, Wu et al. (2016) constructed a Regional Hydrologic Droughts Index (RHDI), obtained the corresponding drought-grade frequency, and then determined the threshold value of the various drought grades based on the cumulative frequency of the RHDI. Tu et al. (2016) constructed the Copula Model of Two-Variable Joint Distribution of hydrologic drought characteristics based on the test method of Cramer-von Mises Statistics associated with Rosenblatt transfer, and analyzed the hydrologic drought characteristics and the drought-response within a changing environment in Dongjiang River Basin. Ren et al. (2016) quantitatively separated the effects of climate change and human activities on runoff reduction based on the Variable Infiltration Capacity (VIC) model, and analyzed the spatial-temporal evolution characteristics of hydrologic droughts by the Standardized Runoff Index (SRI). Li et al. (2016) analyzed the evolution characteristics of the meteorological and hydrological droughts by using Standard Precipitation Evapotranspiration Index (SPEI) and Streamflow Drought Index (SDI), and discussed the responses of hydrological droughts on meteorological droughts. He et al. (2015) analyzed the spatial-temporal characteristics of the meteorological and hydrologic droughts by the Standardized Precipitation Index (SPI), Standardized Discharge Index $(S D I)$ and relative assessing indices, associated with the trend, time lag cross-correlation across the Yellow River Basin (YRB) during the periods 1961-2010. Zhang et al. (2016) constructed the Copula prediction model of hydrologic 
droughts based on the Copula Function and Runoff Distribution Function by the Standard Runoff Index (SRI) according to the seasonal runoff-related characteristics, and discussed an empirical analysis for the hydrologic station of the Aksu

\section{River West Bridge.}

As mentioned above, watershed hydrological drought refers to the phenomena of the stream runoff reduced or cut out, and the water table of lakes or reservoirs dropped due to no or little rainfalls. Therefore, the watershed storage capacity is a key factor for the occurrence of hydrological droughts, and the watershed water storage is more affected by runoff recharge in adjacent watersheds than by rainfall recharge. The watershed landforms are one of the important components of watershed media, and their types and structures affect the runoff recharge of rainfalls and the runoff recharge in adjacent catchments, which is to promote or inhibit the occurrence of hydrological droughts (Feng et al.,1997a). However, except for some relevant research results of He's team (He et al., 2013a, 2013b,2014, 2015,2018a $\& 2018$ b), the present studies on the hydrologic droughts in Karst basins have not seen more detailed study reporting. Thus, this paper is going to take the Guizhou Province of China as the study area where the hydrologic droughts are made the identification and quantification by utilizing the Runoff Drought Severity Index (RDSI) (Feng, 1997a \& 1997b), and to study the driving mechanism of topographic features on hydrological droughts in Karst drainage basins.

\section{Study areas}

Located in Southwestern China, Guizhou Province adjoins Hunan Province to the east, Guangxi Province to the south, Yunnan Province to the west, and Sichuan Province and Chongqing Municipality to the north. Situated on the eastern slope of the Yunnan-Guizhou Plateau, it covers an area of 176, $167 \mathrm{~km}^{2}$, enclosed by coordinate points of $24^{\circ} 37^{\prime} \mathrm{N}$ to $29^{\circ} 13^{\prime} \mathrm{N}, 103^{\circ} 36^{\prime} \mathrm{E}$ to $109^{\circ} 35^{\prime} \mathrm{E}$ (Fig. 1). Greatly determined by the geological structures, the landscape in Guizhou is mainly dominated by basins, hills and mountains with a significant feature of towering mountains, sharp and steep ridges, and significant elevation differences between the valleys and peaks. Guizhou Province is an extremely developed Karst region. The Karst topography reveals a complete demonstration in categories and is widely distributed with an ultimate $73 \%$ of the total area in the form of the carbonate rock outcrops in Guizhou. Since Guizhou Province is located in the subtropical East Asia monsoon regions, the climate type there falls into the category of the subtropical humid monsoon climate in China. In most parts of the province, the climate enjoys a mild humidity with no heavy frost in the winter nor severe heat in the summer, and the four seasons are distinctive. But there is abundant annual rainfall, 
which shows an uneven spatial and temporal distribution with the average annual precipitation between the range of 1100-1300 $\mathrm{mm}$ across the province. The lighting conditions are poor, due to excessive rainy days and high relative moisture, so most parts of the province share 1200-1600 sunshine hours every year. The rivers spread in Guizhou in a dense coverage of $1,1270 \mathrm{~km}$ in length, among which $93 \%$ are over $50 \mathrm{~km}$. The Wumeng Mountain-MiaoLing Ridge Watershed in Guizhou belongs to the Yangtze River and Pearl River basins, where Northern Guizhou stretches to the Jinsha River system, the upper Yangtze River mainstream system, the Wujiang River system and the Dongting Lake water system in the Yangtze River Basin, and where Southern Guizhou reaches to Nanpanjiang River system, Beipanjiang River system, Hongshuihe River system and Duliujiang River system in the Pearl River Basin.

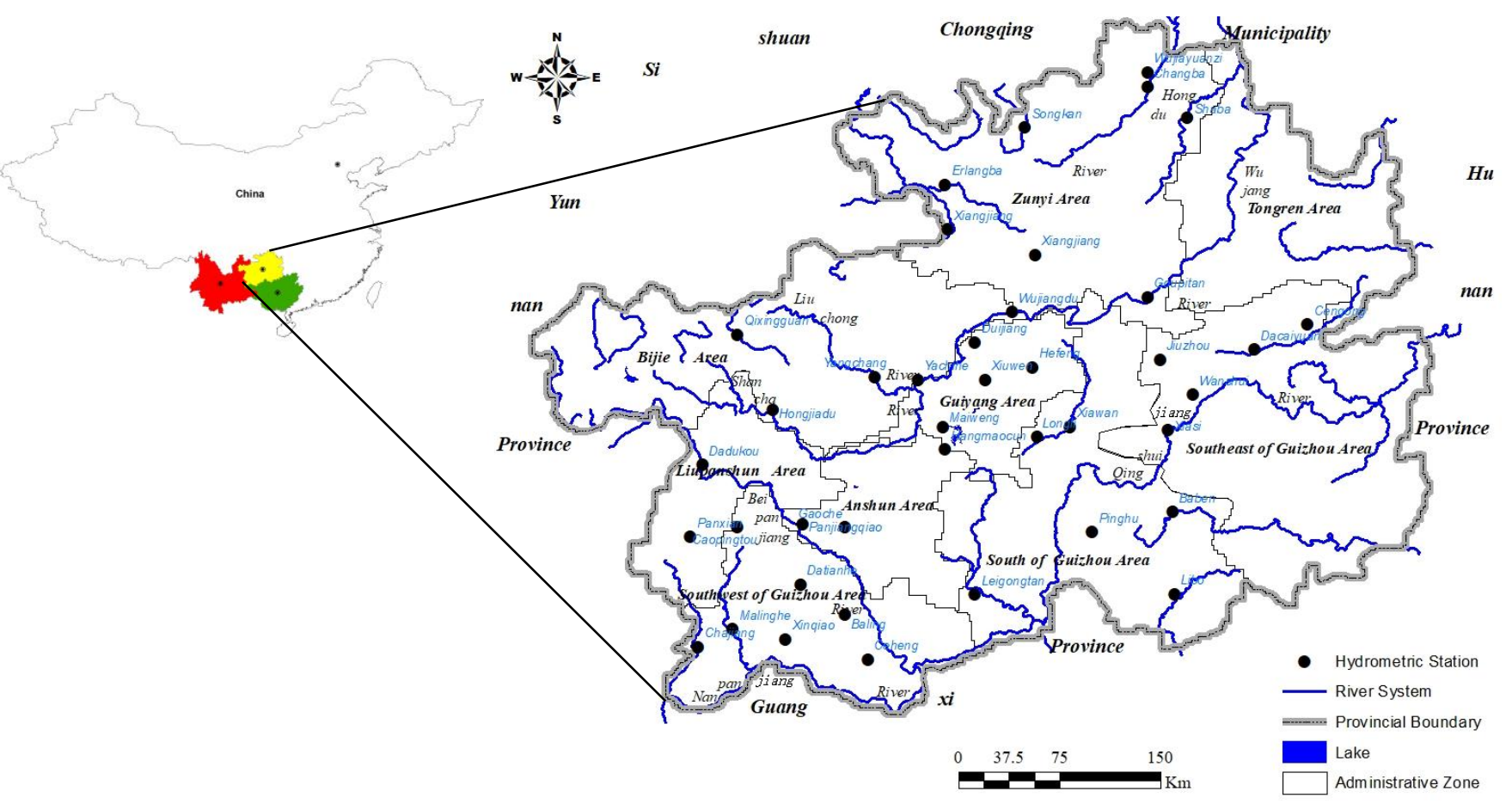

Fig.1 Sketch map of the study area

\section{Research data and methods}

\subsection{Research data}

\section{(1) Hydrological data}

Given the typicality and representativeness as well as the continuity and homogeneity of the hydrological data in this study area, this paper selected the monthly runoff and rainfall measurements of 40 hydrometric stations in Guizhou Province (Fig. 1). Hydrological data were collected from "Guizhou Statistics on Mean Monthly Flows per Calendar Year" compiled by Guizhou hydrologic station, with reference to "Guizhou Water Resource Report" compiled by 
Guizhou Hydrology \& Water Resources Department. We assigned the minimum average monthly runoff and average monthly rainfall per year with the time range from January 2000 to December 2010 .

\section{(2) Remote sensing data}

Taking into account that the evolution of the geomorphology is a slow but prolonged geological process, and that the type and shape of the topography in 2000-2010 remained basically unchanged, we extracted the geomorphological information based on the LS5_TM images of the month corresponding to the minimum monthly mean runoff in 2006 (Time: January to December 2006; Strip Number \& Line Number: 126 129, 040 043; Data Format \& Level: **.geotiff, L4). The Digital Elevation Model (DEM) is based on data provided by the United States Geological Survey (USGS)

(Data Format: Grid; Coordinate System: WGS_84; Spatial Resolution: $30 \mathrm{~m}$ ) .

\subsection{Research methods}

\section{(1) Identification of hydrological drought}

Hydrological drought is a phenomenon that the river flow is lower than its normal value, which means that the river flow cannot satisfy the water supply demand in a certain period (Van Loon et al., 2012, 2015; Mishra, 2010). The run theory (Herbst et al., 1996) was adopted by some scholars to identify hydrologic droughts (Fig.2). For a runoff time series $x(t)$, a significant drought period can be taken as $X(t)<X_{0}(t)$ after applying a truncation level $X_{0}(t)$. The length of negative runs $D\left(X(t)<X_{0}(t)\right)$ is the duration of drought $L$. The total number of negative runs is the total deficit of water for the drought $S$. The intensity of negative runs is the magnitude of drought $M$, indicating the average water deficit volume of the drought period: $M=S / L$.

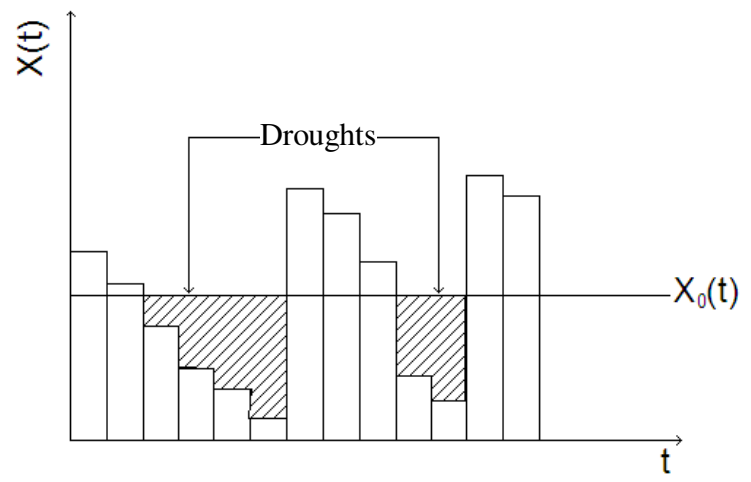

Fig. 2 Identification of hydrologic droughts

In this paper, hydrologic droughts in the Karst drainage basins were identified by using the Mean Monthly Flow 
$(M M F)$ during the yeaas 2000-2010 as truncation level, taking the $M M M F$ of sampling sites as $Y$ axis and the series of sampling sites as $X$ axis. Since Hydrologic Drought Severity (HDS) mainly depends on the volume of water deficit and the length of drought duration, this paper took Relative Drought Severity Index (RDSI) (Feng et al. 1997a) as the measurement of HDS. So the formula for calculating RDSI was presented in the equation below:

$$
R D S I=L D \times D I
$$

Where $L D$ is the relative drought duration within a year (valued as $1 / 12$ in this paper), $D I$ is the relative water deficit of that drought period.

To eliminate the impact of units of measurement for the runoff, the following non-dimensionalization equation was adopted:

$$
D I=\frac{X_{i}-X_{\text {mean }}}{X_{\text {mean }}}
$$

Where $X_{i}$ is the $M M M F$ for sample site $i ; X_{\text {mean }}$ is the $M M F$, viz., the truncation level.

$R D S I$ is a negative value. The larger the absolute value is, the more severe the drought is.

\section{(2) Landform index}

This paper processed the spectral radiance and apparent reflectance of remote sensing data corresponding to the minimum average monthly runoff depth of the hydrological station in 2006, and extracted the sample sites controlled by the hydrologic cross-section. The object-oriented classification technique was used to extract the Geomorphic Type Indicators (GTI) and Landform Index ( $L I)$, based on the GTI and $L I$ (Tab.1 and Tab.2) (MA et al., 2012), in reference to "Guizhou Geomorphology Map" (internal data) compiled by Guizhou Normal University.

\begin{tabular}{|c|c|c|c|c|c|}
\hline $\begin{array}{l}1^{\text {st }} \text { grade } \\
\text { landforms }\end{array}$ & $\begin{array}{l}1^{\text {st }} \text { grade classification. } \\
\text { criteria } \\
\text { Depth of dissection, } \\
\text { surface } D(m)\end{array}$ & $\begin{array}{l}2^{\text {nd }} \text { grade } \\
\text { landforms }\end{array}$ & $\begin{array}{l}2^{\text {nd }} \text { grade classification } \\
\text { criteria } \\
\text { Absolute altitude } \mathrm{H}(\mathrm{m})\end{array}$ & $\begin{array}{l}3^{\text {rd }} \text { grade } \\
\text { landforms }\end{array}$ & $\begin{array}{l}3^{\text {rd }} \text { grade classification } \\
\text { criteria } \\
\text { Depth of dissection, } \\
\text { surface } \mathrm{D}(\mathrm{m})\end{array}$ \\
\hline Basin & $\begin{array}{l}\mathrm{S}<9^{\circ} \\
\mathrm{D}<100\end{array}$ & $\begin{array}{l}\text { Depression } \\
\text { Low } \\
\text { Medium } \\
\text { High }\end{array}$ & $\begin{array}{l}\text { Slope of basin bottom } \\
\mathrm{H}<900 \\
900 \leq \mathrm{H}<1900 \\
1900 \leq \mathrm{H}\end{array}$ & \multicolumn{2}{|c|}{$<5^{\circ}$ and area $<1 \mathrm{~km}^{2}$} \\
\hline Hill & $9^{\circ} \leq \mathrm{s}<14^{\circ}$ & $\begin{array}{l}\text { Medium } \\
\text { High }\end{array}$ & $\begin{array}{l}\mathrm{H}<900 \\
900 \leq \mathrm{H}<1900 \\
1900 \leq \mathrm{H}\end{array}$ & $\begin{array}{l}\text { Shallow } \\
\text { Deep } \\
\text { Shallow } \\
\text { Deep } \\
\text { Shallow } \\
\text { Deep }\end{array}$ & $\begin{array}{l}\mathrm{D}<200 \\
200 \leq \mathrm{D} \\
\mathrm{D}<200 \\
200 \leq \mathrm{D} \\
\mathrm{D}<200 \\
200 \leq \mathrm{D}\end{array}$ \\
\hline Mountain & $14^{\circ} \leq \mathrm{S}$ & $\begin{array}{l}\text { Low } \\
\text { Medium }\end{array}$ & $\begin{array}{l}\mathrm{H}<900 \\
900 \leq \mathrm{H}\end{array}$ & $\begin{array}{l}\text { Low } \\
\text { Mid } \\
\text { High }\end{array}$ & $\begin{array}{l}900 \leq \mathrm{H}<1400 \\
1400 \leq \mathrm{H}<1900 \\
1900 \leq \mathrm{H}\end{array}$ \\
\hline
\end{tabular}

Tab. 1 Basic classification of landforms

Tab. 2 Indices for landform classification

\begin{tabular}{llcc}
\hline Name & Formula & Range & Description \\
\hline
\end{tabular}




\begin{tabular}{|c|c|c|c|}
\hline \multirow[t]{2}{*}{ symmetry } & $2 \sqrt{\frac{1}{4}(\operatorname{Var} X+\operatorname{Var} Y)^{2}+(\operatorname{Var} X Y)^{2}-\operatorname{Var} X \operatorname{Var} Y}$ & \multirow[t]{2}{*}[0,1]{} & \multirow{2}{*}{$\begin{array}{l}\text { VarX: Variance in } \mathrm{X} \text { direction } \\
\text { VarY: variance in Y direction. } \\
\text { Eigenvalue rises with symmetry }\end{array}$} \\
\hline & $\operatorname{Var} X+\operatorname{Var} Y$ & & \\
\hline & & \multirow{4}{*}{$\begin{array}{l}{[0, \text { a value determined }} \\
\text { by the shape of image } \\
\text { object }]\end{array}$} & $\begin{array}{l}\sqrt{\# P_{v}} \text { : diameter of square object containg } \\
\# P_{v} \text { pixel. }\end{array}$ \\
\hline $\begin{array}{ll}\text { Square } & \text { fit } \\
\text { index } & \text { (or }\end{array}$ & $\sqrt{\# P_{v}}$ & & $\sqrt{\operatorname{Var} X+\operatorname{Var} Y}:$ diameter of the ellipse \\
\hline density & $1+\sqrt{\operatorname{Var} X+\operatorname{Var} Y}$ & & $P_{v}:$ image object $\mathrm{V}$ expressed in pixels \\
\hline & & & $\begin{array}{l}\text { The more the image object resembles a } \\
\text { rectangle in shape the higher its } \\
\text { characteristic value, }\end{array}$ \\
\hline $\begin{array}{l}\text { Rectangle } \\
\text { fit index }\end{array}$ & $\frac{\#\left\{(x, y) \in P_{v}: \rho_{v}(x, y) \leq 1\right\}}{\# P_{v}}-1$ & $\begin{array}{l}{[0,1] .1: 100 \% \text { fit, }} \\
0: 0 \% \text { of pixels fit into } \\
\text { the rectangle }\end{array}$ & $\begin{array}{l}\rho_{v}(x, y): \text { rectangular distance at a pixel } \\
(\mathrm{x}, \mathrm{y}) .\end{array}$ \\
\hline $\begin{array}{l}\text { Ellipse fit } \\
\text { index }\end{array}$ & $2 \cdot \frac{\#\left\{(x, y) \in P_{v}: \varepsilon_{v}(x, y) \leq 1\right\}}{\# P_{v}}-1$ & $\begin{array}{l}{[0,1], 1: 100 \% \text { fit, } 0: \leq} \\
50 \% \text { of pixels fit into } \\
\text { the ellipse. }\end{array}$ & $\begin{array}{l}\varepsilon_{v}(x, y) \text { :ellipse distance at a pixel }(\mathrm{x}, \mathrm{y}) \\
P_{v}: \text { image object } \mathrm{V} \text { expressed in pixels } \\
\# P_{v}: \text { image object } \mathrm{V} \text { expressed in pixels }\end{array}$ \\
\hline
\end{tabular}

Note: Definiens Developer7 Reference Book was consulted for this index

\section{Results and analysis}

\subsection{Spatial pattern of Geomorphological distribution in Guizhou}

\subsubsection{Distribution characteristics of geomorphologic types in Guizhou}

Guizhou landform is dominated by the mountain, followed by the hill and basin. Among them, the $23.37 \%$ and $16.94 \%$ of areas are the low-medium and mid-medium mountains in the mountainous regions, followed by the low and high-medium ones with the areas of $10.96 \%$ and $4.93 \%$ respectively. On the other hand, most of the hills are the low hill (22.06\%), mid-hill (9\%), and high hill (3.09\%). There are the more low basins $(4.86 \%)$ than medium ones $(0.51 \%)$ and high ones $(0.25 \%)$, and the less the depressions $(0.012 \%)$. Guizhou is a mountainous province with the mountain and hill all over the province. With the exceptions of a few regions like Liupanshui and Anshun regions where the mountain is rarely found, but the hill is distributed in a large proportion across the province, and their distributions showing a certain symmetry. Especially hilly distributions are shown no or little phenomena in the Zunyi areas and Southwestern parts. Meanwhile the basin is seldom appeared in Guizhou, as well as no distributions in the southwestern Guizhou, Liupanshui, Anshun Area and parts of Zunyi (Fig. 3a).

\subsubsection{Relieffeatures of landforms in Guizhou}

The changing trend of Topographic Relief Degrees (TRD) of the mountains is basically consistent with that of the hills in Guizhou.The largest TRD of the mountains is presented in Dadukou, Shuicheng (relative relief $1898 \mathrm{~m}$ ), Panxian (relative relief $1885 \mathrm{~m}$ ) and Chajiang, Xinyi (relative relief $1842 \mathrm{~m}$ ), while the maximum TRD of the hills in 
Maiweng, Pingba (1518 m), and Hefeng, Kaiyang (896.4 m) and Xiawan, Guidiing (870.28 m) (Fig. 3b).

\subsubsection{Morphological Features of landforms in Guizhou}

The Symmetry Index $(S I)$ of the three geomorphological types is about 0.6 in terms of morphological index, indicating that it is presented a certain symmetry of morphological distributions in the mountain, hill and basin regions with the SIs of 0.4-0.8, 0.2-0.9, and 0.4-1 respectively (Fig. 3c). The Square Fitting Indices (SFIs) (Density Indexes) of the mountain, hill and basin are all fluctuating around 1.5, indicating that three of them are shown the squareness distributions. In general, The SFI of hills is greater than that of the mountain, indicating that the hilly morphology is closer to square than the mountain (Fig. 3d). The Rectangle Fitting Index (RFI) of hilly landforms is generally greater than that of the mountains, and that of mountainous landforms is $0.4-0.7$ (Fig. 3e). Similarly, the Elliptic Fitting Index $(E F I)$ of hilly landforms is generally greater than that of the mountains. The EFIs of the hill and basin are sharply fluctuating from 0 to 0.6 and from 0 to 0.7 respectively (Fig. 3f). To sum up, the four Morphological Indices (MIs) of three geomorphologic types are basin $>$ Hill > mountain.
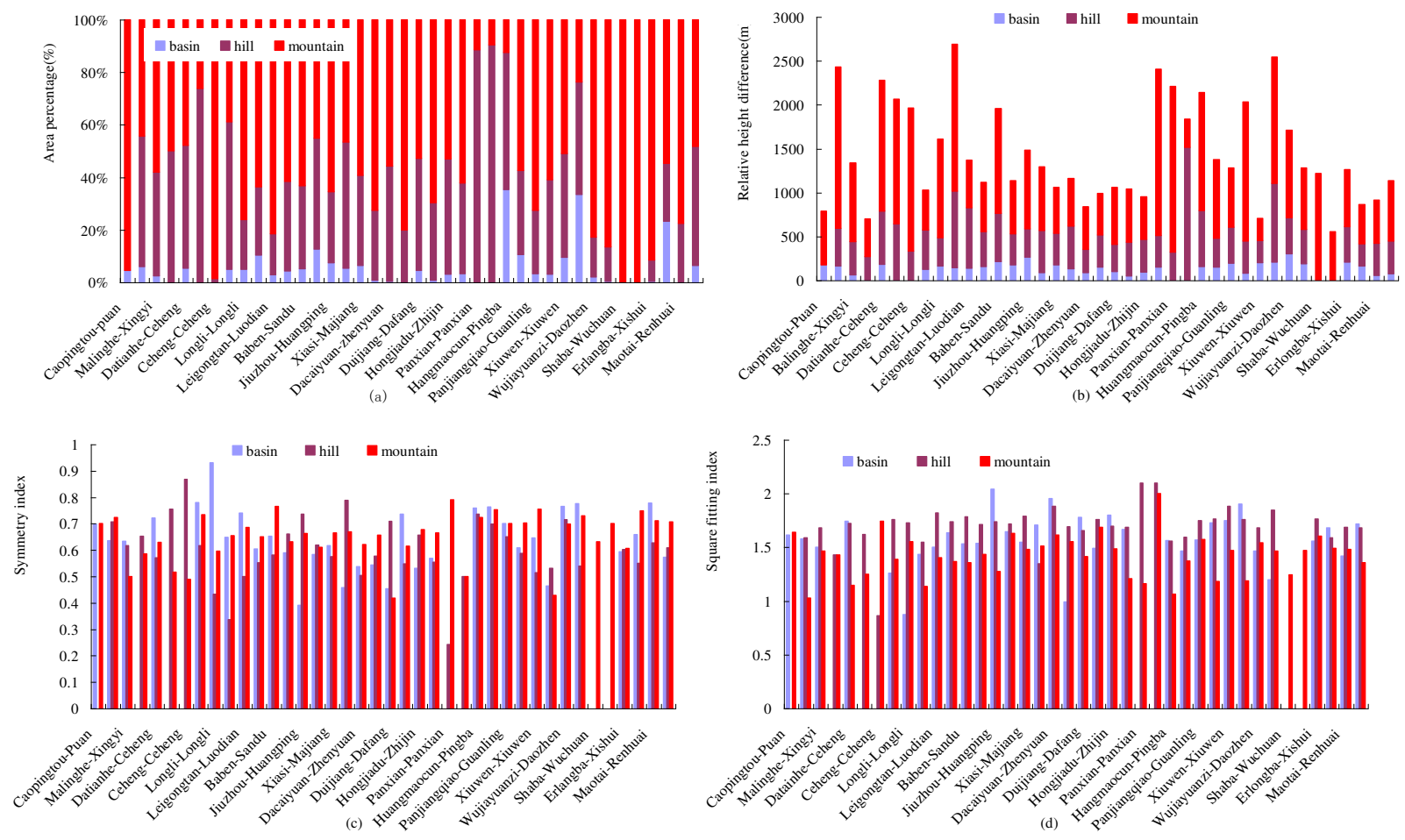

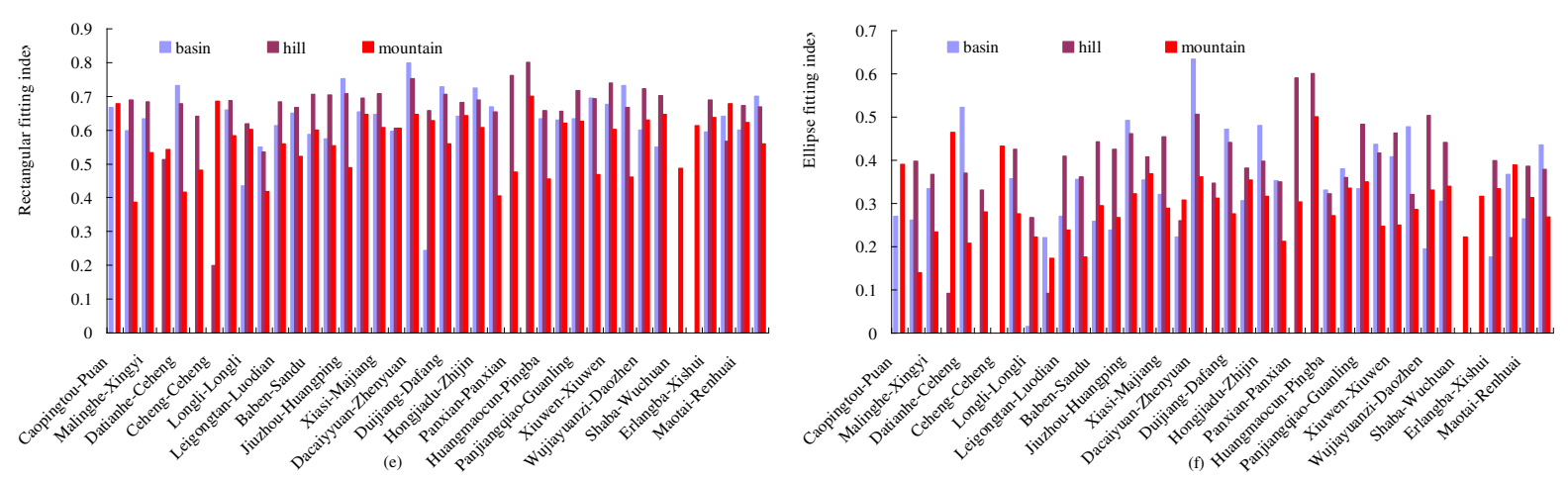

Fig.3 The overall distribution of landform types

\subsection{Hydrologic drought characteristics in Guizhou}

\subsubsection{Inter-annual variation characteristics of hydrological drought}

The hydrologic drought severity in Guizhou was increasing year by year during the periods 2000-2010. The most serious hydrologic drought was found in the 2010 (RDSI=-0.634), followed by the 2005 (RDSI =-0.591) and the 2009 $(R D S I=-0.555)$, and the least serious one in the $2000(R D S I=-0.528)$. The inter-annual variations of hydrological droughts in Guizhou from the 2000 to 2010 had the obvious phase characteristics, and these can be divided into three phases and four periods, in which the first transitional phase was in the 2000-2001 (relative annual rate was 10.13\% ), the second one in the 2004-2005 (annual relative variability of 11.09\%), the third one in the 2009-2010 (annual relative variability of $18.76 \%$ ), whereas the first period of droughts was in 2000,the second one in the 2001-2004, the third one in the 2005-2009, and the fourth one in 2010 (Fig.4a).

The Coefficient of Variation $\left(C_{v}\right)$ of hydrological droughts in Guizhou was appeared an obvious inter-annual variability during the periods 2000-2010, with the trend of decrease year by year. The changing within the year of hydrologic droughts was larger in the $2000\left(C_{v}=-0.685\right)$ and $2004\left(C_{v}=-0.65\right)$ than in the $2010\left(C_{v}=-0.385\right)$ and 2001 $\left(C_{v}=-0.487\right)$. The inter-annual differences of $C_{v}$ values of regional hydrological droughts were significant with the peak of the annual relative variability $66.11 \%$ in the $2000-2001$, the second peak $(51.04 \%$ ) in the $2009-2010$, and the third one (30.94\%) in the 2004-2005. The changing direction between the RDSIs and $C_{v}$ s is opposite, that is, the greater the $R D S I$, the smaller the $C_{v}$ (2010), whereas the smaller the $R D S I$, the greater the $C_{v}$ (2000). The inter-annual variation trend of the RDSIs is opposite to the $C_{v}$ S (Fig.4a).

\subsubsection{Spatial distribution of hydrologic drought}

The overall regional distribution of hydrological droughts in Guizhou is presented a pattern in this way: it is more severe in the south than in the north, and less severe in the east than in the west (Fig. 4b). The most serious areas of hydrological droughts are appeared in the Southwestern Guizhou Province, and the relatively less severe ones are found 
in the Zunyi Region. The regional variation of $C_{v}$ values of hydrological droughts is divided into two sections: the Curve-type in the first half of the section, and the W-shaped type in the second half, and that of $C_{v}$ values is relatively smaller in South Guizhou than in other parts in Guizhou. For instance, the $C_{v}$ value is the negative maximum (-1.595) in Liupanshui, and the minimum (0.207) in Zunyi. The hydrologic drought severity is gradually increasing along the Northeast-Southwest Direction (Fig. 4c) with a light Wave-type distribution, and the regional variation of $C_{v}$ values is larger, and shows an $N$-type distribution. The RDSI values of watershed hydrological droughts are all less than -0.44 along the Northwest-Southeast Direction (Fig. 4d), North-South (Fig.4e) and Western Directions (Fig.4f), and the hydrologic drought severity is more and more serious and is showing a linear distribution with the fitting indices $R^{2}=0.995, R^{2}=0.9978$ and $R^{2}=0.3794$ respectively. The $C_{v}$ values of regional hydrological droughts vary greatly, and show a $V$-shaped distribution. The hydrologic drought severity is gradually decreasing in the Southern Direction (Fig.4g), and shows a linear distribution $\left(R^{2}=0.9633\right)$ with the smaller $C_{v}$ value.
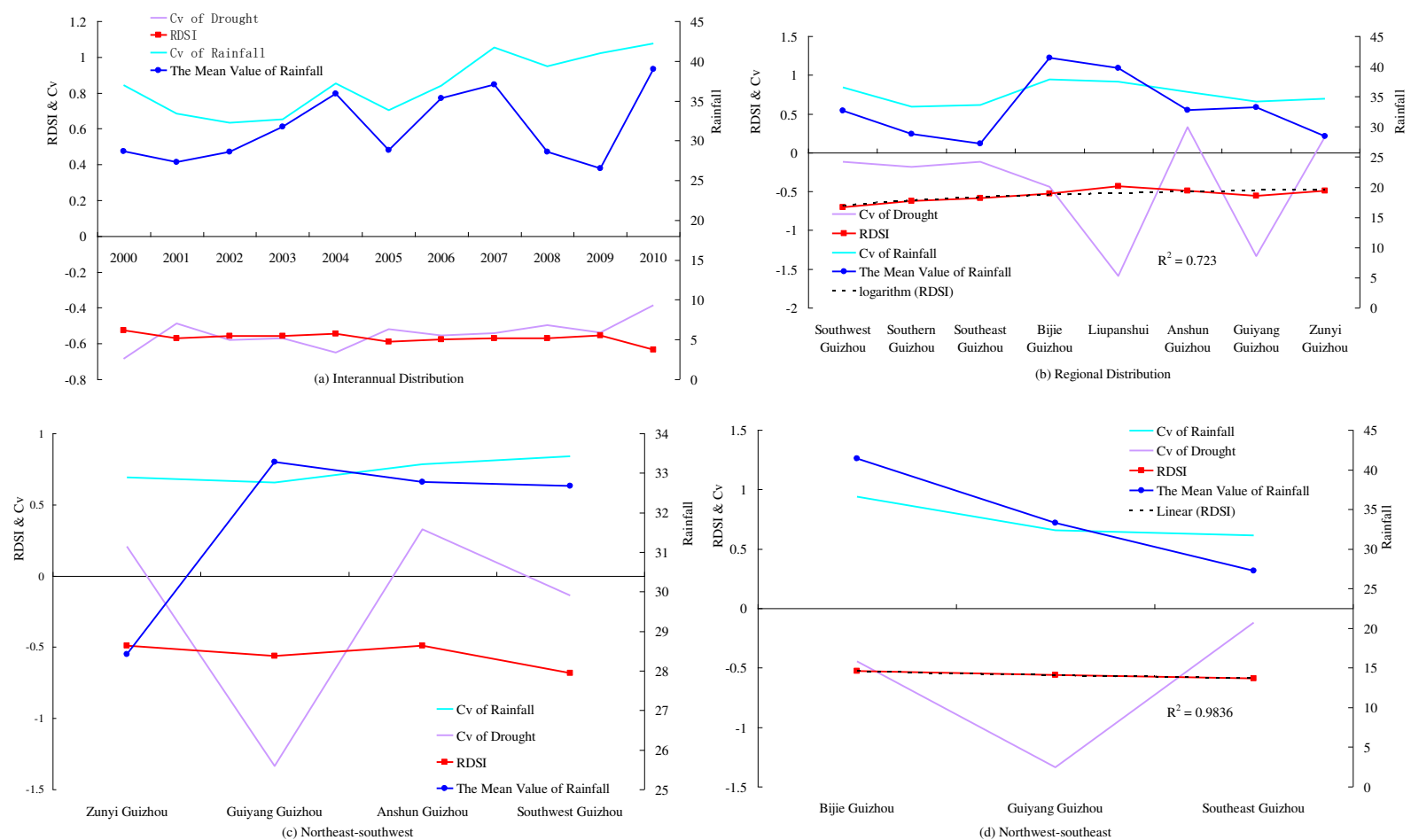

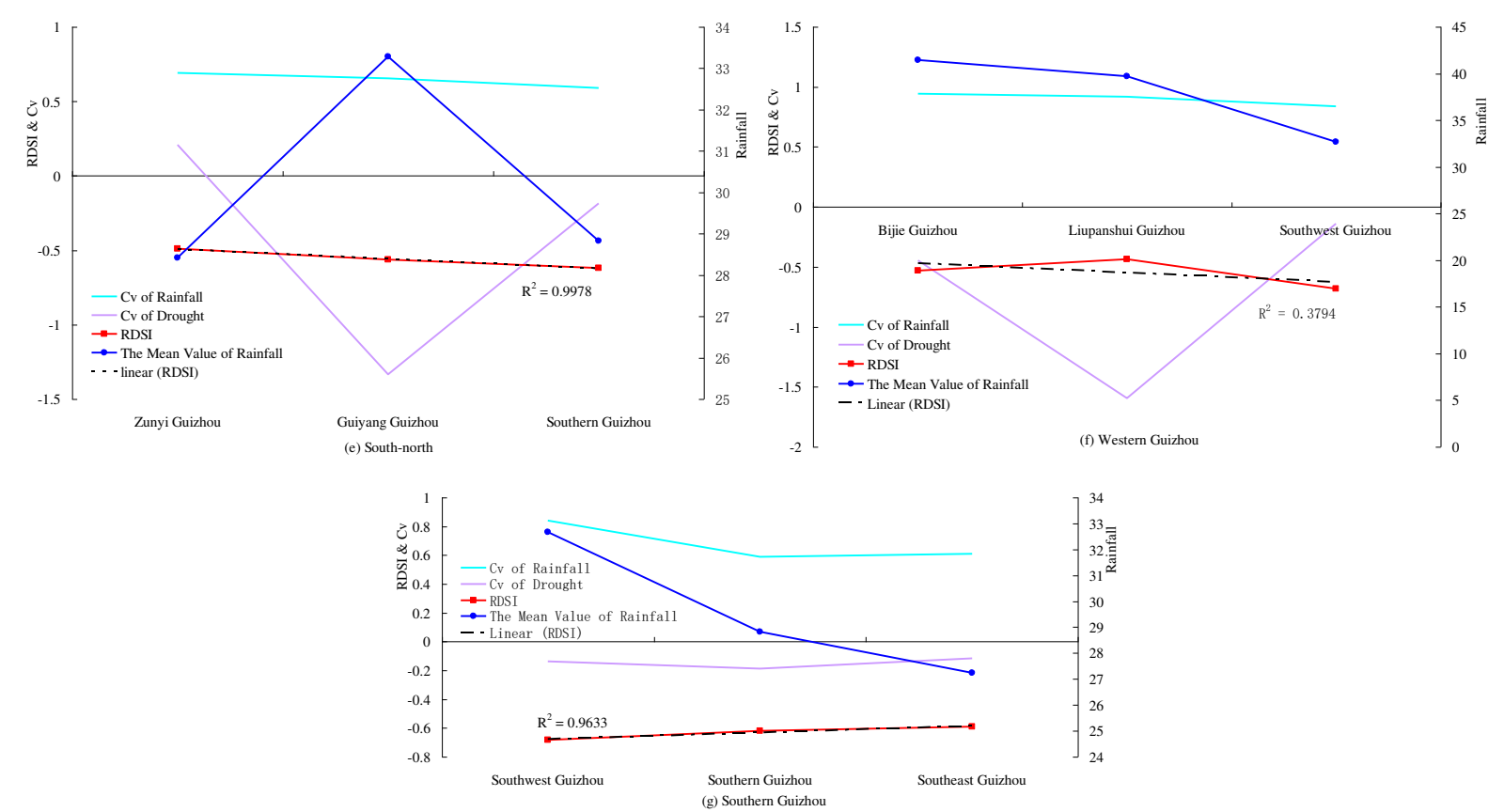

Fig.4 The spatial and temporal distribution of hydrological droughts and impacts of rainfall factors

\subsection{Driven mechanism of watershed hydrological drought}

\subsubsection{Driven mechanism of rainfall factors on hydrological drought}

\section{(1) Inter-annual changes driven of rainfall factors on hydrologic drought}

Watershed hydrological drought refers to a phenomenon of the water shortage of basins and the runoff reduction or cut-off of rivers due to the water storage capacity of the underlying surface factors when the rainfall volume is comparatively lower (or constant). Feng et al., (1997a) pointed out that the runoff volume in the dry period is mainly coming from the water-retained volume in the catchments at the end of the flood season, and the rainfall volume in the low-flow season, and the former is accounting for a larger proportion. As can be seen from Fig.4a, the mean rainfall in the driest months was increasing year by year from the 2000 to 2010, but hydrological drought severity was more serious year by year, which indicates that the impact of rainfalls in the dry period on hydrologic droughts is smaller with the $R=-0.468(P=0.147)$ between $R D S I$ and mean rainfall. For example, the average value of rainfalls in the driest months was $38.949 \mathrm{~mm}$ with the $R D S I=-0.634$ in the 2010 ,and $28.651 \mathrm{~mm}$ with the $R D S I=-0.528$ in the 2000 . The differences of mean rainfalls in the driest months were larger in the 2001-2004 and 2005-2009, and that of hydrologic drought severities was smaller. The inter-annual variability of $C_{v}$ values was larger for the mean rainfall in low flow months of the 2000-2010, and showed an increasing trend (Fig .4 a), while that of $C_{v}$ values was smaller for the 
hydrologic droughts, and presented a decreasing trend, which indicates that the change of rainfalls in the dry period has less impact on that of hydrologic drought severities with the $R=0.323(P=0.332)$. Similarly, the $C_{v}$ value of mean rainfalls in the driest months was $1.075,0.843$ in the 2010 and 2000 respectively, and that of RDSIs was $-0.385,-0.685$. The inter-annual variability of $C_{v}$ values was larger for the mean rainfall in the driest months of the 2005-2008,and that of $C_{v}$ values was smaller for the hydrologic drought severities.

\section{(2) Regional change driven of rainfall factors on hydrologic drought}

The spatial distribution of the mean rainfalls in the driest months varies greatly in Guizhou, showing a Hump type (Fig.4b),and that of RDSIs varies very small, presenting a logarithmic distribution with the $R^{2}=0.723$.It indicates that

the spatial distribution of rainfalls in the driest months has little impact on that of the RDSIs, with the $R=0.4$ ( $P=0.326)$, and that the $C_{v}$ of rainfalls has little impact on the $C_{v}$ of hydrological droughts $(R=-0.27, P=0.518)$.The impact of $C_{v}$ value of rainfalls on the $C_{v}$ value of hydrologic droughts is smaller with the $R=-0.27(P=0.518)$. As can been seen from the spatial distribution (1) that of rainfalls changes a lot in the driest months and appears a single-peak type along the Northeast-Southwest (Fig.4c) and North-South Directions (Fig.4e),and the impact of rainfall volumes on hydrologic droughts is small with the $R=-0.454(P=0.546)$ and $R=-0.122(P=0.922)$ respectively; the spatial variation of $C_{v}$ value of rainfalls has less influence on that of $C_{v}$ value of hydrologic droughts, with the $R=-0.55(P=0.45)$ and $R=0.87$ ( $P=0.945)$; (2) the spatial variation of rainfalls is small along the Western Direction (Fig.4f),showing a decreasing trend, and the influence of rainfalls on hydrologic droughts is not significant with the $R=0.841(P=0.364)$; in other words, there is no linear correlation between the $C_{v}$ of rainfalls and the $C_{v}$ of hydrological droughts $(R=-0.478$, $P=0.683$ ); and (3)the rainfall volume drops drastically in the Northwest-Southeast (Fig.4d) and Southern directions (Fig.4g), showing a significant impact on the hydrological droughts with $R=0.998(P=0.041)$ and $R=-0.999(P=0.028)$ respectively; however the $C_{v}$ of rainfalls has no significant impact on that of hydrologic droughts with the $R=0.135$ $(P=0.913)$ and $R=0.302(P=0.805)$ respectively.

\subsubsection{Driven mechanism of geomorphological features on hydrologic drought}

\section{(1) The driven of landform types on hydrologic drought}

The watershed runoff recharge is mainly coming from the atmospheric precipitation at the end of the flood season and the runoff recharge in the adjacent catchments (the non-closed catchment) due to the no or little rainfall in the Karst basins in the dry periods. Therefore, landform types play an important role on watershed runoff recharges. The Landform Morphologies (LM), Topographic Relief Degrees (TRD) (Ma et al., 2012) and Surface-Dissection Depths 
$(S D D)$ are quite different as for the different types of landforms, which greatly influences the lateral or vertical flow of rainfalls on the surface and underground and the secondary distribution of atmospheric precipitation in the catchments. It is be related to the occurrence of hydrological droughts. There is a certain correlation between RDSIs and distribution areas of the mountain, hill and basin in terms of the overall distribution of the landform types in Guizhou, with the $R_{(\text {mountain })}=-0.399, R_{(\text {hill })}=-0.212$ and $R_{(\text {basin })}=0.209$ respectively. Except for the basin, the hilly and mountainous areas do not pass the significant test $(p>0.05)$. The correlation between single landform type and RDSI can be divided into three sections (Fig. 5a): the basin section (V-type), the hilly and mountainous sections (Growth-type).In the basin section, the correlation is the smallest in the low basin areas with the $R=-0.291(P=0.069)$, the largest in the high basin areas with the $R=0.478(P=0.002)$.In the hilly section, the correlation is the shallow-low hilly area $(R=-0.24$, $P=0.134)<$ deep-medium hilly area $(R=0.177, P=0.273)<$ deep-high hilly area $(R=0.523, P=0.001)$.In the mountainous section, the correlation is larger in the high-medium mountain $(R=0.414, P=0.008)$ than in the low mountain $(R=-0.073$, $P=0.653)$. The $R D S I$ value of hydrological droughts is negative, that is, the greater the negative, the more serious the hydrological drought is. Therefore, the larger the Rs between the geomorphic types and RDSIs are, the more significant the influences of the geomorphic types on the hydrological droughts are, and the less serious the hydrological droughts are. On the contrary, the greater the negative $R s$ between the geomorphic types and RDSIs are, the more significant the influences of the geomorphic types on the hydrological droughts are, and the more serious the hydrological droughts are. In summary, the Rs between the high-medium mountain, deep-high hill and high basin and RDSIs are above 0 with $\mathrm{p}<0.001$, which indicates that it is the relatively lighter areas of hydrologic droughts in the high-medium mountain, deep-high hill and high basin. Meanwhile the negative $R s$ are found in the low basin, shallow-low hill and low mountain, where the hydrological droughts are the relatively more serious areas. The Rs between geomorphic types and RDSIs in the basin, hill and mountain range from negative to positive and then increase with the elevation increasing, which means that the watershed hydrological droughts are getting less severe with the altitude increasing.

\section{(2) The driven of landform dissection depths on hydrologic drought}

The lateral flow of atmospheric precipitation on the surface is more affected by the Surface Relief $(S R)$ or Surface-Dissection Depth $(S D D)$ than by the geomorphic types. For example, For example, the deeper the $S D D$ is, the greater the $S R$ is, with the $R_{\text {basin }}=0.842, R_{\text {hill }}=0.982$ and $R_{\text {mountain }}=0.362$ between the $S D D s$ and $S R s$ respectively. The longer the rainfall confluence on the surface is, the more the rainfall infiltration is, as well as the lighter the hydrological drought is. The Rs between the SDDs and RDSIs could be divided into three sections: the basin and mountainous sections (showing V-type), the hilly section (showing W-type) shown as Fig.5a. Similarly, the largest impacts of the $S D D s$ on hydrologic droughts are found in the high basin, deep-high hill and high-medium mountain with the $R=0.536$ $(P<0.001), R=0.568(P<0.001)$ and $R=0.557(P<0.001)$, and the smallest impacts in the low basin, deep-low hill and 
low-medium mountain with the $R=0.148(P=0.361), R=-0.092(P=0.572)$ and $R=-0.104(P=0.522)$ respectively. This indicates that the relatively lighter areas of hydrological droughts are observed in the high basin, deep-high hill and high-medium mountain, while the relatively serious areas in the low basin, shallow-low hill, and low-medium mountain. It may be that the deepening surface will delay the runoff and confluence times of rainfalls on the surface and underground, and enlarge the volume of infiltration, which causes the hydrological droughts relatively lighter. The $R s$ between RDSIs and SDDs ranging from depression to high-medium mountain is to generally increase, which means that watershed hydrologic droughts are shown the getting lighter and lighter in the depression to high-medium mountain.

\section{(3) The driven of geomorphological features on hydrologic drought}

Another important characteristic indices of landform types are the MIs, such as the $S I$, the $S F I(D I)$, the $R F I$ and the EFI, which will reflect the complexity degree of geomorphological features and distributions and the development degree of rivers on the surface and underground. The Fig.5b is shown the correlations (Rs) between the RDSIs and four indexes of geomorphological features. Similarly it is divided into three sections: showing a growth-type in the basin and hilly sections and a W-type in the mountainous section. In general, the Rs between the RDSIs and four indexes of geomorphological features are Basin Section (0.399)> Hilly Section (0.389)>Mountainous Section (0.253). The $R s$ between the RDSIs and four types of MIs are above 0 in the depression to high-medium mountain (except for the low-medium mountain), especially the larger $R$ values in the depression to deep-high hill and it means that there are different influences of morphological distribution on hydrologic droughts. The largest $R$ values between the RDSIS and four types of MIs are found in the high basin, deep-high hill, and high-medium mountain with the significance probability $P<0.001$, in which the relatively lighter areas of hydrological droughts are. The $R s$ between $R D S I s$ and four types of MIs are the smaller in the mid-medium mountain, especially the smallest $R$ between the RDSI and EFI in the low-medium mountain. It indicates that the most serious areas of hydrological droughts are appeared in the low-medium and mid-medium mountains.
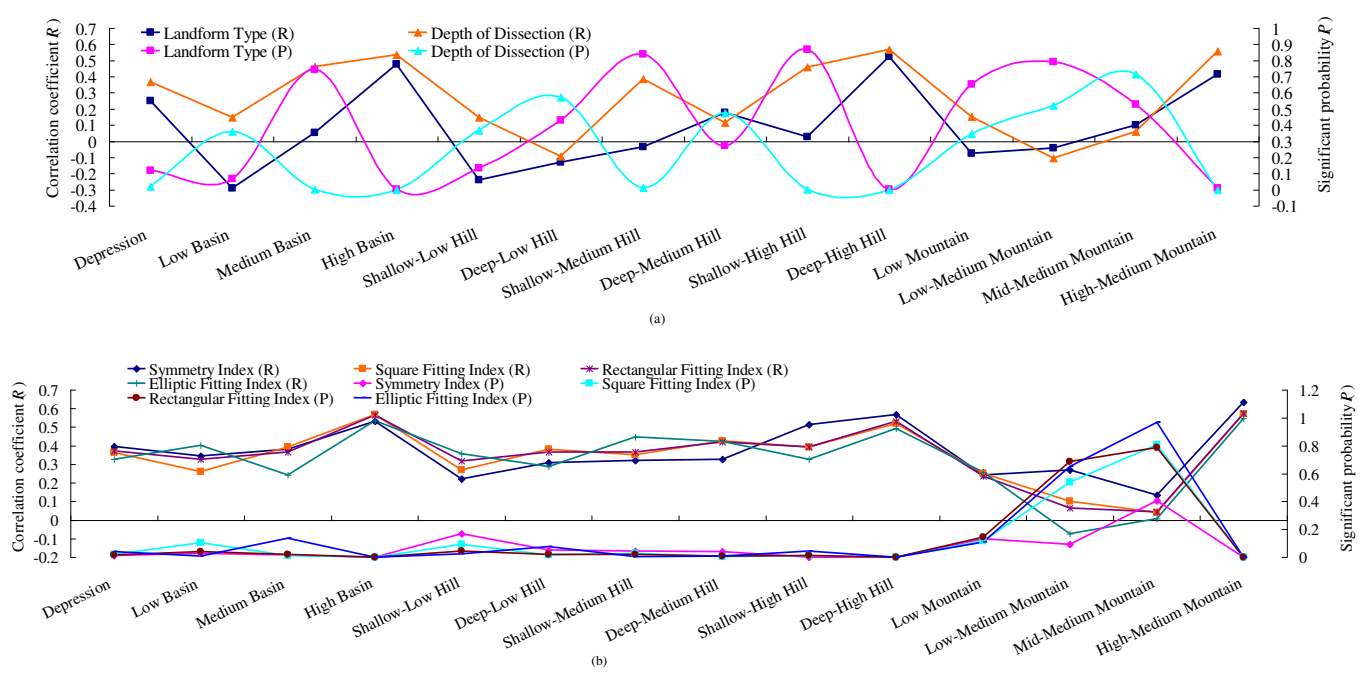
Fig.5 The correlation coefficients between landform types and hydrological droughts

\subsubsection{Driven mechanism of drought variability on hydrologic drought}

\section{(1) The inter-annual variability driven of droughts on hydrologic drought}

Hydrological drought, considered as the final and most complete form of droughts, is the continuation and development of meteorological and agricultural droughts. Once hydrological drought happens, and it demonstrates that (1)the precipitation has been abnormally lower; 2the catchment has a water deficit and a lower groundwater storage; and (3)the irrigation is no longer possible (Geng et al., 1992). The occurred hydrologic droughts will produce the devastating damage on the watershed ecological environments. It mainly shows that the soil water content or soil water-holding capacity is decreased sharply, even reached the level of wilting coefficient, and it is difficult to supplement physiological water requirement of plants, which will result in the drying and death of large area crops or vegetation, and the decline phenomenon of vegetation coverage. In addition to those results, the soil and rock of the catchments are exposed and scorched, thereby producing a lot of sand and dust and aggravating the greenhouse effects. The serious damage of the water storage media will result in the reduction of the water storage capacities, which is an important factor leading to the occurrence of hydrological droughts. The correlation analysis was carried out for the RDSIs from the 2000 to 2010s in this study, and the correlation coefficients $(R s)$ were above $0.501(P<0.001)$, which proves that the inter-annual interaction of hydrologic droughts was particularly significant during the years 2000-2010.

\section{(2) The regional variability driven of droughts on hydrologic drought}

The Karst drainage basin is a "binary vs. three-dimensional space structure" with the binary media and dual water systems. The Karst drainage basins are classified into the Surplus Basin, Balanced River Basin and Deficit Basin based on the closed degree between the surface and underground water systems (Yang,1982). For one thing, the watershed water storage in the dry season is the main source of runoff recharge in Karst basins. Therefore, the large (small) of runoff volumes in dry season is influenced by the strong (weak) of watershed water storage capacities, which is directly related to the occurrence of hydrological droughts. For the other, the watershed storage capacity is greatly affected by the water-stored media and its water systems. The type, size and amount of water-stored spaces are influenced by the watershed water-stored media, which will affect the volume of watershed water storage. The water system is the channels of energy flow and information flow, which reflects the secondary distribution of rainfalls on the surface and is also the key factor of watershed water balance. The rainfall during the dry periods has little influence on the surface runoff in Karst basins, and runoff recharge is mainly coming from the volumes of water storage in the basins and from that in the adjacent basins. Therefore, hydrologic droughts in the adjacent basins have significantly influences on each other. Such as the Bijie Region and Guiyang City $(R=0.832, P=0.01)$, Bijie Region and Anshun Region $(R=0.816$, 
$P=0.014)$, and Anshun Region and Guiyang City $(R=0.753, P=0.031)$, because they belong to neighboring areas in terms of administrative divisions, which may result in the exchange of groundwater due to a non-enclosed between the surface and underground systems. The inter influence of hydrological droughts is very small or not if there is no exchange of groundwater and no loss of surface water, even in the adjacent areas, such as Qianxinan Region and Anshun Region $(R=-0.199, P=0.637)$.

\section{Discussion}

It is well known that, in terms of economic costs, social problems and impacts on ecological environments, drought is one of the most destructive natural disasters. At the same time, the drought phenomena are very complex, and droughts are considered to be the most complex, least understood and most influential natural disasters. The drought occurrence indicates that there is no rainfall or very little rainfall in a period of times. However, no or very little rainfall in a period of times does not necessarily mean that droughts will occur, especially the hydrological droughts (only when runoff of the surface and underground rivers decreased or cut off, and water table of the lakes or reservoirs dropped). Therefore, compared with rainfall, drought occurrence will delay a certain periods, and the lag time and intensity are greatly affected by the watershed storage capacity. Previous studies (Feng et al.,1997a) demonstrate that the runoff in the dry season mainly comes from the volume of water storage in the basins at the end of the flood season and the volume of rainfall in the dry season, while the volume of water storage in the basins is mainly determined by the rainfall in the flood season and the underlying surface medium factors. Therefore, the mean rainfall in the driest month was shown the increasing year by year from the 2000 to 2010 in Guizhou, while watershed hydrologic drought severity was becoming more and more serious, with the $R-0.468(P=0.147)$, This indicates that the rainfall during the dry period has less effect on hydrological droughts. Meanwhile, the inter-annual variability of $C_{v}$ values of rainfalls was larger in the driest month during the years 2000-2010 with an increasing trend, and that of $C_{v}$ values of RDSIs was smaller with a decreasing trend. This means that the impact of rainfall changes during the dry periods on hydrologic drought changes is very small with the $R=0.323(P=0.332)$. In addition, the spatial distribution of mean rainfalls varies greatly in the driest month in Guizhou and presents a Hump pattern, while that of the RDSIs changes little and shows a logarithm type. This indicates that the spatial distribution of rainfalls in the driest month has little influence on that of the $R D S I S$ ( $R=0.4$, $P=0.326)$. It may be due to the fact that droughts generally occur in the low flow seasons with high water demand, and the rainfall deficit is only a necessary inadequate conditions. So droughts are less affected by rainfall deficit than by watershed water storage. while the watershed storage capacities are deeply affected by the types and structures of catchment media.

The basin geomorphology is one of important components of watershed media, and their types and structures will influence the secondary distribution of atmospheric precipitation on the surface. Especially the morphological 
characteristics of landform types will play a critical role on the lateral and vertical flows of rainfalls on the surface and underground, which influences the confluence and runoff times of rainfalls on the surface. For the different types of landforms, such as the mountain, hill and basin, they have great differences in the elevation, slope, SDD and $S R$, which affects on the secondary distribution of rainfalls and the watershed storage capacities. For example, a higher elevation, larger slope, and deeper surface dissection, and larger Surface Relief are found in the mountain, in which the rainfall velocity is particularly faster. On the contrary, a lower elevation, smaller slope, and shallower surface dissection, and smaller surface relief are observed in the basin,where the rainfall velocity is relatively slower. This study proves that the Rs between the RDSIs low basin, shallow-low hill and low mountain are the smallest, and the largest in the high basin, deep-high hill, and high-medium mountain respectively. Meanwhile, the positive Rs are found in the high basin, deep-high hill, and high-medium mountain, and the negative $R s$ in the low basin, shallow-low hill, and low mountain. Indicating that the relatively lighter areas of hydrologic droughts are appeared in the high-medium mountain, deep-high hill, and high basin, and just the opposite in the low basin, shallow-low hill, and low mountain. This may be cause that the elevation increasing, surface dissection deepening, and surface relief increasing will result in the erosion or dissolution base levels and groundwater tables deepened in the catchments, and the watershed thicknesses increased, as well as the vertical distances from the watershed surfaces to erosion or dissolution base levels increased. Thus, there are amount of water-stored spaces and particularly stronger storage capacities in the catchments, where the lighter hydrological droughts are. Conversely, the vertical distances from the watershed surfaces to erosion or dissolution base levels are smaller, and the watershed thicknesses are very thinner. However, there are less water-stored spaces and relatively weaker storage capacities in the catchments, where the serious hydrologic droughts are.

Another important factor affecting the runoff of rainfalls on the surface and underground is the geomorphic morphological characteristics (i.e., Morphological Index, $M I$ ), such as the $S I, S F I(D I), R F I$ and $E F I$, which of them is the most effective quantitative description of geomorphic morphological characteristics. For instance, the larger the $M I s$, the more regular the distribution of geomorphic shapes, the simpler the distribution of geomorphic edges, which of them results in the closer between the surface and underground systems (for Karst drainage basins), the less the outflow water, and the smaller the probability of hydrological droughts. This study proves that the $M I$ effects of three landform types on hydrological droughts are basin>hill >mountain, and these of single landform on hydrological droughts are high basin, deep-high hill and high-medium mountain>medium basin, shallow-medium hill and low-medium mountain $>$ low basin, shallow-low hill and mid-medium mountain. It may be that watershed hydrological droughts are more influenced by the watershed elevation, $S D D$ and $S R$ than by the morphological characteristics of geomorphologies. In other words, the runoff of rainfalls on the surface and underground is mainly affected by the morphological distributions of geomorphologies, and the retained flow of rainfalls on the surface and underground is mainly influenced by the 
watershed elevation, $S D D$, and $S R$, which will affect the watershed storage capacities. Meanwhile, the inter-annual variations and regional differences of hydrological droughts are also important driving factors. It may be due to the time lag of hydrological drought occurrences compared with the rainfalls, as well as the watershed runoff recharges coming from the rainfall volume in the dry season and another from the runoff recharge in adjacent catchments.

\section{Conclusions}

The watershed landforms are one of important component factors of catchment media, and the landform types and spatial distribution pattern will influence the secondary distribution of rainfalls on the surface and underground, and the watershed storage capacity, which will be related to the occurrence of hydrological droughts. The results of this study demonstrate that:

(1) Guizhou landform is dominated by the mountain, followed by the hill and basin. Among them, the mountain is dominated by the mid-medium mountains, followed by the low and high-medium mountains; the hilly areas are dominated by the low hill, followed by the medium and high hills; the most low basin in the basin areas, followed by the medium and high basins. The Topographic Reliefs in Guizhou Province are the larger, showing the spatial distribution pattern of the larger in the centre than in the east, the smaller in the Northeast than in the Southwest. The types of Guizhou landforms are various and morphology complex, and the MIs is basin>hill>mountain.

(2) The impacts of the rainfall and its change on hydrologic drought and its change are smaller in the low flow seasons with the no or little rainfall. For example, the mean rainfalls in the driest months were increasing year by year during the years 2000-2010 in Guizhou, and the hydrologic droughts were aggravating year by year; the inter-annual variations of $C_{v}$ values of rainfalls in the driest months are larger with an increasing tread, while these of $C_{v}$ values of hydrological droughts are smaller with a decreasing tread. The regional distributions of hydrological droughts are shown the more serious in the South than in the North, and the less serious in the East than in the West. Therefore, the rainfall deficit is only a necessary and insufficient condition of drought occurrence.

(3) The watershed landforms play a crucial role on the secondary distribution of rainfalls on the surface and underground, and the watershed elevation, Surface-Dissection Depth, Surface Relief and morphological characteristics are the controlling factors for hydrological drought occurrences. For instance, the vertical distances from watershed surfaces to erosion or dissolution base levels are increasing with the watershed elevation increasing, the Surface-Dissection deepening and Surface Relief increasing, which will result in the watershed water-stored spaces increasing, the watershed storage capacities strengthening, and the hydrological droughts relatively lighter. On the contrary, the hydrological droughts are more serious. Meanwhile, the inter-annual variation and regional difference of hydrological droughts are also one of important driving factors. 


\section{Acknowledgments}

The authors are grateful to the editors and the anonymous reviewers for their precious suggestion and comments. This study was sponsored by the Natural Science Foundation of China (41471032; u1612441); Project for National Top Discipline Construction of Guizhou Province (85 2017 Qianjiao Keyan Fa); Project of National Key Innovation Base Construction （Qiankeheji Lab [2011]4001); Natural and scientific research fund of Guizhou Water Resources Department (KT201402); Natural and scientific fund of Guizhou Science and Technology Agency (QKH J [2010] No. 2026, QKH J [2013] No. 2208); 2015 Doctor Scientific Research Startup Project of Guizhou Normal University.

\section{References}

Abebe A., Foerch G.,2008.Stochastic simulation of the severity of hydrological drought. Water and Environment Journal,22(1):2-10.https://doi.org/10.1111/j.1747-6593.2007.00080.x.

Dracup A., Lee K., Paulson J E G.1980. On the definition of droughts . Water Resources Management, 16(2):297-302. https://doi.org/10.1029/WR016i002p00297.

EU:2006.Water Scarcity and Droughts-Second Interim Report,European Commission,DG Environment,Brussels.

EU:2007. Addressing the challenge of water scarcity and droughts in the European Union, Communication from the commission to the European Parlement and the Council, European Commission,DG Environment,Brussels.

Feng G., 1993.An analysis of frequency of critical drought duration in independent hydrologic sesies. Agricultural Research in the Arid Areas,11(3): 60-68.

Feng P.,Wang R.,1997a. Investigation on the Time Fractal of Hydrologic Drought. Water conservancy and Hydropower Technology, (11):48-51.

Feng P., and Jia H.,1997b. Inverstigation on forecastiong model of hydrological drought in water supply systems. Journal of Tianjin University, 30(3): 337-342.

Feng G.,1995. An analysis frequency of critical hydrologic drought duration.SHUILI XUEBAO, (6):37-41. 
Feng G.,1994. A STUDY ON PROBABILITY DISTRIBUTION OF CRITICAL HYDROLOGEIC DROUGHT DURATIONS USING THE METHODS OF ANALYTICS AND SIMULATION. ACTA GEOGRAPHICA SINICA,49(5):457-468

Fleig A., Tallaksen L., Hisdal H.,2011. Regional hydrological drought in north-western Europe: linking a new Regional Drought Area Index with weather types. Hydrological Processes, 25:1163-1179.https://doi.org/10.1002/hyp.7644.

Guven O.,1983. A simplified semiemprical approach to probabilities of extreme hydrologic droughts. Water Resource Research,19(2):441-453. https://doi.org/10.1029/WR019i002p00441.

Geng H.,Shen B.,1992.Definition and Significance of Hydrologic Droughts.Aricultural Research in the Arid Areas, 10(4):91-94.

Hao Z.,Hao F.,Singh V.,etc.,2016.Probabilistic prediction of hydrologic drought using a conditional probability approach based on the meta-Gaussian model.Journal of Hydrology,542:772-780. https://doi.org/10.1016/j.jhydrol.2016.09.048.

Hisdal H., Tallaksen L. M.,2003.Estimation of regional meteorological and hydrological drought characteri-stics: a case study for Denmark. Journal of Hydrology,281(3):230-247. https://doi.org/10.1016/S0022-1694(03)00233-6

Herbst P., Bredenkamp D., Barker H.,1996.A technique for the evaluation of drought rainfall data. Journal of Hydrology, 4(4):264-272.

He Z., Liang H., Yang C., etc., 2018a.Temporal - spatial evolution of the hydrologic drought characteristics of the karst drainage basins in South China. International Journal of Applied Earth Observation and Geoinformation, 64:22-30. http://dx.doi.org/10.1016/j.jag.2017.08.010

He Z., Liang H., Yang C., etc., 2018b. Water System Characteristics of Karst River Basins in South China and Their Driving Mechanisms of Hydrological Drought. Nat Hazards,Published online:19 March 2018.

https://doi.org/10.1007/s11069-018-3275-2

He Z.,Chen X., and Liang H.,2015. Studies on the mechanism of watershed hydrologic droughts based on the combined structure of typical Karst lithologys.CHINESE JOURNAL OF GEOLOGY, 50(1):340-353.https://doi.org/10.3969/j.issn.0563-5020.2015 .01 .023 .

He Z.,Chen X., and Liang H.,2014. Study on Spatial Pattern of Land-using Types and Hydrologic Droughts for Typical Karst Basin 
of Guizhou Province . Journal of China Hydrology, 34(1):20-25.

He Z., and Chen X.,2013a. The Hydrological Drought Simulating in Karst Basin Based on Coupled Soil Factors——Taking Guizhou Province as A Case. Scientia Geographica Sinica, 33(6):724-734.

He Z.,Chen X.,and Liang H.,2013b. The Hydrological Drought Analysis of the Karst Basin Based on the Soil Systematic Structure-Taking Guizhou Province as a Case. Journal of Natural Resource, 28(10):1731-1741.

https://doi.org/10.11849/zrzyxb.2013.10.008.

Kim T., Valdés J.,2006.Nornparametric Approach for Bivariate Drought Characteriztion Uing Palmer Drought Index. Journal of Hydrologic Engineering,11(2):134-143.

Li Y., He J., Li X., 2016. Hydrological and meteorological droughts in the red river basin of Yunnan Province based on SPEI and SDI Indices. Progress in Geography,35(6):758-767. https://doi.org/10.18306/dlkxjz.2016.06.009.

Mondal A., Mujumdar p.,2015. Return levels of hydrologic droughts under climate change. Advances in Water Resources,75:67-79. https://doi.org/10.1016/j.advwatres.2014.11.005.

Ma S., An Y.,2012.Auto-classification of Landform in Karst Region Based on Aster GDEM. Scientia Geographica Sinica,32(3):368-373.

Mishra A.,Singh V., 2010.A review of drought concepts. Journal of Hydrology, 391:202-213.

Nyabeze W., 2004. Estimating and interpreting hydrological drought indices using a selected catchment in Zimbabwe. Physics and Chemistry of the Earth,29:1173-1180. https://doi.org/10.1016/j.pce.2004.09.018.

Panu U., Sharma T., 2009.Analysis of annual hydrological droughts: the case of northwest Ontario,Canada. Hydrological Sciences Journal, 54(1):29-42. http://dx.doi.org/10.1623/hysj.54.1.29.

Rudd A., Bell V., Kay A.,2017.National-scale analysis of simulated hydrological droughts (1891-2015).Journal of hydrology,550:368-385.http://dx.doi.org/10.1016/j.jhydrol.2017.05.018.

Ren L., Shen H.,Yuan F., etc., (2016). Hydrological drought characteristics in the weihe catchment in a changing environment.Advances in Water Science,27(4):492-500. https://doi.org/10.14042/j.cnki.32.1309.2016.04.002. 
Sheffield J., Wood, E., 2011. Drought, Past Problems and Future Scenarios, Earthscan.

Sen Z.,1977. Run-sums of annual flow series. Journal of Hydrology,35(3):311-324. https://doi.org/10.1016/0022-1694(77)90009-9.

Sen Z.,1990. Critical drought analysis by second-order Markov chain. Journal of hydrology,120:183-202.

https://doi.org/10.1016/0022-1694(90)90149-R.

Sen Z.,1991.On the probability of the longest run length in an independent series. Journal of Hydrology,125:37-46.

https://doi.org/10.1016/0022-1694(91)90082-S.

Sharma T.,1998. An analysis of non-normal Markovian extremal droughts. Hydrology Process,12:597-611.

Seibert M.,Merz B.,Apel H.,2017.Seasonal forecasting of hydrological drought in the Limpopo Basin:a comparison of statistical methods.Hydrol. Earth Syst. Sci., 21:1611-1629. https://doi.org/10.5194/hess-21-1611-2017.

Tu X., Chen X.,Zhao Y., etc., 2016. Responses of hydrologic drought properties and water shortage under changing environments in Dongjiang River Basin. Advances in Water Science,27(6):810-821.

https://doi.org/10.14042/j.cnki.32.1309.2016.06.003.

Van Loon A.F.,Laaha G., 2015.Hhydrological drought severity explained by climate and catchment characteristics.Journal of Hydrology, 526:3-14. https://doi.org/10.1016/j.jhydrol.2014.10.059

Van Loon A. F.,Van Lanen A., 2012.A process-based typology of hydrological drought.Hydrol.Earth Syst.Sci., 16:1915-1946. https://doi.org/10.5194/hessd-8-11413-2011.

Van Huijgevoort M., Van Lanen, H.A.J., Teuling, A.J., etc., 2014.Identification of changes in hydrological drought characteristics from a multi-GCM driven ensemble constrained by observed discharge. Journal of Hydrology, 512(6):421-434. http://dx.doi.org/10.1016/j.jhydrol.2014.02.060

Van Lanen H., Wanders N., Tallaksen L.,etc., 2013.Hydrological drought across the world: impact of climate and physical catchment structure.Hydrol. Earth Syst. Sci.17,1715-1732. http://dx.doi.org/10.5194/hess-17-1715-2013.

Yevjevich V., 1967.An objective approach to definition and investigations of continental hydrologic droughts, Colorado State University. 
Yang M.,1982.The Geomorphological Regularities of Karst Water Occurences in GuiZhou Plateau.Carologica Sinica, (2):81-91.

Wu J., Chen X., Gao L., etc., 2016.Construction and Recognition of Regional Hydrological Drought Index Based on Standardized R unoff Index. Mountain Research,34(3):282-289. https://doi.org/10.16089/j.cnki.1008-2786.000129.

Wen L., Rogers K., Ling J., etc., 2011.The impacts of river regulation and water diversion on the hydrological drought characteristics in the Lower Murrumbidgee River, Australia. Journal of Hydrology, 405(3):382-391.

Zhou Y.,Yuan X.,Jin J.,2011. Regional Hydrological Drought Frequency Based on Copulas.SCIENTIA GEOGRAPHICA SINICA, 31(11):1383-1388.

Zhai J., Jiang G., Pei Y.,etc.,2015. Hydrologic drought assessment in the river basin based on Standard Water Resources Index (SWRI):a case study on the Northern Haihe River. Shuili Xuebao,46(6):687-698.https://doi.org/10.13243/j.cnki.slxb.20140844.

Zhao X.,Zhao R., 2016. Applicabiltity Applicability of the hydrologic drought index in the upper Fenhe River.Advances in Water Science,27(4):512-519. https://doi.org/10.14042/j.cnki.32.1309.2016.04.004.

Zhang Y., Xiang L., Sun Q., etc.,2016. Bayesian Probalilistic Forecasting of Seasonal Hydrological Drought Based on Copula Function. Scientia Geographica Sinica,36(9):1437-1444. https://doi.org/10.13249/j.cnki.sgs.2016.09.017. 